\title{
A Meta-Analysis of Association Between the MMP-13 rs2252070 Promoter Polymorphism and Cancer Risk
}

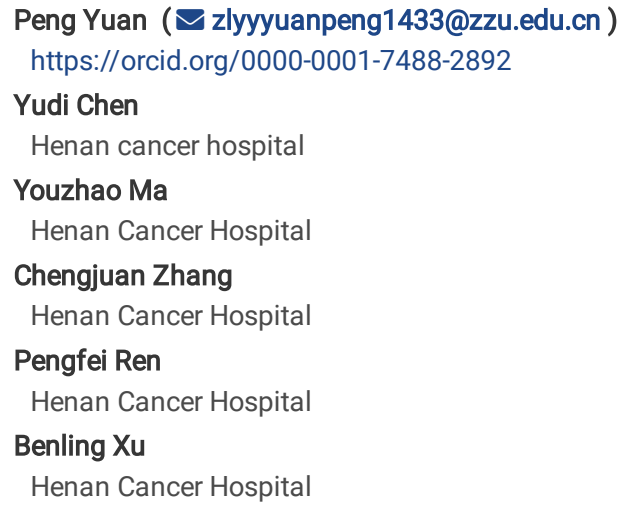




\section{Abstract}

Background Originally detected in breast cancer tissue, MMP-13 has been showed to be closely related to cancer development. Increasing evidence has also suggested that rs2252070, one of its SNP, can profoundly influence cancer risk by regulating the expression while the conclusion still remained controversial. Therefore, this meta-analysis was conducted to assess the carcinogenesis effect of this SNP quantitatively. Methods Studies about association between rs2252070 polymorphism and cancer risk by March 15, 2020 had been collected in PubMed, Web of Science, Cochrane Library and CNKI. R scripts and STATA software were applied to calculate estimates. Pooled ORs and corresponding 95\% Cls were used to evaluate the strength of association. Results Twenty studies meeting pre-defined criteria were retrieved for the final statistical analysis, including 8,215 cancer patients and 8,480 healthy controls. The pooled estimates revealed no statistical significance for the association between this polymorphism and the risk of cancer in all 5 genetic models. Similarly, no significance had been detected in stratified analyses by region, cancer type, sample size and genotyping method. Conclusion The association between MMP13 rs2252070 and carcinogenesis was not statistically significant. To elucidate this conclusion, future studies including gene-gene and gene-environment interaction are needed to verify the study results.

\section{Background}

Collagenase-3, a member of matrix metalloproteinases, is widely distributed in various tissues and organs and can degrade multiple components of basement membrane and extracellular matrix, including collagen I, II, III, VII, X and other proteoglycans[1, 2]. It's a Z $\mathrm{n}^{2+}$ dependent matrix metalloproteinase and normally inactive. Besides activating other subtypes of MMPs (such as MMP-2 and MMP-9), it can also be activated by other MMPs (such as MMP-2 and MMP-3) [3]. Therefore, slight changes in the activity or expression level of MMP-13 can be amplified by influencing the activation of other ECM decomposition enzymes. Because of participating in the degradation of ECM, it is considered to play an important role in various pathological processes like rheumatoid arthritis and liver fibrosis[4]. Originally identified in breast cancer tissues, increasing evidence has also suggested that this enzyme is closely related to cancer development $[5,6]$. By comparing the level of collagenase- 3 in normal and cancer tissues, the result demonstrated that the content of this enzyme in normal tissues is extremely low $[7,8]$. And other researchers had found that there is a positive correlation between collagenase-3 level and tumor aggressiveness[9].

Encoding collagenase-3, the MMP-13 gene is located on 10q22 and consists of 10 exons and 9 introns[10]. As mentioned above, even the smallest variation of genome, such as single nucleotide polymorphism, may significantly affect the regulation of MMP-13. At present, 3662 single nucleotide polymorphisms of MMP-13 have been reported, of which rs2252070 ( $>$ $>$ ), located 77 bps upstream of the promoter region, is the most widely studied one. In vitro, it has been proved that the $\mathrm{G}$ allele of rs2252070 had significantly lower corresponding promoter activity, approximately half of A allele[11]. Consequently, this A to $\mathrm{G}$ SNP has been linked to lower cancer susceptibility by influencing the expression level of MMP-13. Given the essential biological effects of rs2252070, it is necessary to evaluate its carcinogenic impact. Some researchers had already investigated the relationship between this SNP and cancer risk in various cancers such as lung cancer, gastric cancer, colorectal cancer, liver cancer and prostate cancer[12, 13].However, due to the unavoidable differences in research design and implementation, the research results were incongruous and there's no consensus has been reached about the impact of MMP-13 rs2252070 on carcinogenic risk by far. Therefore, to summarize the existed evidence and draw a more credible conclusion, we performed this meta-analysis based on current relevant datasets.

\section{Materials And Methods}

\section{Searching Strategy}

Pertinent studies about association between MMP-13 rs2252070 polymorphism and cancer risk were identified through searching in web of Science, PubMed $\square$ Cochrance Library $\llbracket$ CNKI And Wanfang Data. The Boolean query formula was composed of following three keyword parts: cancer ("neuroblastoma", "melanoma”, "lymphoma”, "osteosarcoma”, "leukemia", "tumor", "cancer", "carcinoma" and "adenocarcinoma"), polymorphism ("polymorphism", "SNP", and "variant") and polymorphism ID, gene name and symbol ("MMP13", "MMP-13", "matrix metalloproteinase-13", and "rs2252070"). All articles identified by our searching strategy were published before March 15, 2020.

\section{Eligibility Criteria}

Titles and abstracts of all relevant papers were reviewed by three auxiliary members respectively. For a study to be included in this meta-analysis had to meet the following pre-defined inclusion criteria: (1) manuscripts published on peer-reviewed journals; (2) case-control studies search on the effect of $M M P-13$ rs2252070 polymorphism on the susceptibility of malignant tumors; (3) researches with enough genotype data to calculate or value and $95 \%$ confidence interval in at least one genetic model; (4) the case group does not contain any benign tumor samples. According to the literature screening criteria described in the previous section, we preliminarily screened out the irrelevant research that obviously needs to be excluded, and then read the full text and check the data to determine whether to include it.

\section{Data Extraction}

Retrieval work of this study was conducted by three reviewers independently. Group discussion would be organized to reach an agreement in case of inconsistent information about screening results. And if there was overlapping or duplication data in different researches, the most recent publication or that with the largest study population would be selected for our meta-analysis. For each study, the following information were documented : a) first author's surname (b) year of publication (c) the geographical area of samples involved (d) the frequency of polymorphism in the case group and the control group (E) the sample size (f) the genotyping method $(\mathrm{g})$ the cancer type. In addition, the deviation from Hardy Weinberg equilibrium (HWE) in each study was measured statistically $(P<0.05$ indicates statistical significance), and then was qualitatively marked as the study characteristic. 


\section{Statistics Analysis}

Association between cancer risk and rs2252070 polymorphism were analyzed by pooling odds ratio (ORs) and corresponding $95 \%$ confidence interval (Cls) in five genetic models including allele model ( $G$ vs $A$ ), dominant model ( $A G+G G$ vs $A A)$, recessive model ( $G$ vs $A G+A A)$, heterozygous model ( $A G$ vs $A A)$ and homozygous model (GG vs AA). Cochran's $Q$ test was performed to assess the state of heterogeneity between studies, with a significance level of 0.10 . Between-study heterogeneity was not considered to be significant when $P_{h}<0.10$, and the data would be pooled by the fixed effects (Mantel-Haenszel) algorithm[14]. Otherwise, random effects (DerSimonian and Laird) model would be adopted to calculate and 95\% confidence interval[15]. Galbraith plot was generated to directly find out which studies significantly contribute to the overall heterogeneity[16]. Moreover, in order to explore the source of heterogeneity further, subgroup analyses were performed for cancer type (lung cancer, digestive system cancer or others), region (Asian or others), sample size (greater than 1000 or not), and method of genotyping (PCR-RFLP or others). To evaluate the potential publication bias quantitatively, Begg's test and Egger's test were both conducted and the threshold set as $0.05[17,18]$. Also, corresponding funnel plots were applied to demonstrate the degree of publication bias visually. (Studies with larger sample population and higher-quality were distributed at the bottom of funnel, whereas those with smaller sample population and lower precision were located closer to the horizontal axis). Additionally, the sensitivity analysis was carried out to make sure the stableness of our study by using the leaveone-out method. All statistical tests were performed by applying our pre-developed R script (version 3.5.2) and STATA software (version 14.2).

\section{Results}

\section{Characteristics of Included Studies}

A total of 139 publications were preliminarily obtained by applying our searching strategy in five databases. Twenty-two studies were remained for further examination after the duplication removal and initial screening. While performing the final eligibility checking, we found that three ovarian cancer datasets from the Fourth People's Hospital of Hebei Medical University overlapped. According to our strategy, the two studies published earlier with smaller sample sizes were excluded, and the latest research data from December 2001 to December 2008 were retained[19].

Finally, 20 publications were qualified for the statistical analyses, including 4 in Chinese and 16 in English[19-39]. A total of 16,995 samples were enrolled, including 8,215 cancer patients in the case group and 8,480 healthy people in the control group. Among all the eligible papers, thirteen of them were conducted in China and seven others had people from Greece, Spain, Turkey, Sweden, Mexico, Polish and Brazil involved. And all studies were published between 2006 and 2019. The literature retrieval and screening process are shown in Figure 1. The basic characteristics of the included literatures are shown in Table 1.

\section{Main Analysis Results}

As demonstrated in Table 2, all the 95\% confidence interval of the combined estimates contained OR $=1$, indicating no statistically significant association between this polymorphism and cancer susceptibility (allele model: OR = 0.99, 95\% Cl 0.89-1.10; homozygous model: OR =0.96, 95\% Cl 0.78-1.17; heterozygous model: $\mathrm{OR}=1.00,95 \% \mathrm{Cl}$ 0.91-1.10 Figure 2; dominant model: OR = 1.00, 95\% Cl 0.88-1.13; recessive model: OR = 0.98, 95\% Cl 0.83-1.16)

Subsequently, subgroup analyses for cancer type, origin area, genotyping method and sample size had been conducted to assess the impact of rs2252070 on cancer risk further. When stratified by cancer types, no significant association had been detected in the digestive system cancer group. Similarly, it revealed no significance in both lung cancer group and other cancer group. Next, in the analyses based on origin area and genotyping method, the pooled results also showed that this polymorphism had no significant effect on cancer incidence. Finally, we assessed the associations in sample size subgroups and set cut-off at $200,400,500,600,800$ and 1000 respectively. However, the effect of rs 2252070 polymorphism on cancer risk was still not statistically significant by applying all cut-offs.

\section{Publication Analysis and Sensitivity Analysis}

In order to validate the robustness of our study, the sensitivity analysis was conducted by leave-one-out method (Figure 3). By removing one certain study each time and re-calculating the summary statistic successively, the pooled ORs did not materially altered, showing that our results were not subject to any certain research.

In addition, when applying Begg's test for appraisal of the publication bias, no significance in all genetic models had been detected. While when Egger's test was used, there was significant publication bias in homozygous model $(P=0.030$, Figure 4$)$ and recessive model $(P=0.019$, Figure 5). Asymmetric distribution was also observed in the corresponding funnel diagram. Using trim-fill method, four suppositional studies were added in homozygous model and five were added in recessive model severally. Moreover, the re-calculated OR value and corresponding $95 \% \mathrm{Cl}$ remained stable (homozygous model: OR $=1.09$, $95 \%$ Cl: $0.88-1.35$; recessive model: $\mathrm{OR}=1.15,95 \% \mathrm{Cl}$ : 0.96-1.37).

\section{Between-study Heterogeneity Analysis}

Based on the criterion of heterogeneity $P$-value greater than 0.1 , significant heterogeneity was observed in all five genetic models (allele model $P_{h}<0.01$; homozygous model $P_{h}<0.01$; heterozygous model $P_{h}=0.06$; dominant model $P_{h}<0.01$; recessive model $P_{h}<0.01$ ). Therefore, all of the analyses were conducted by applying the random effects model.

Since heterogeneity in the subgroup could not be completely eliminated in subgroup analyses, therefore, we drew Galbraith plots to find out the source of heterogeneity between studies. Eight studies [24-26,30,33,34,36,39] in the allele model, seven studies [24-27,32,36,39] in the homozygous model, one study [35] in the heterozygous model ( Figure 6 ), five studies in the dominant model, and six studies $[24-26,32,36,39]$ in the recessive model have been identified as the main causes of between-study heterogeneity. 
After removing these data sets, no significant heterogeneity was detected (allele model $P_{h}=0.75$; homozygous model $P_{h}=0.20$; heterozygous model $P_{h}=$ 0.31; dominant model $P_{h}=0.36$; recessive model $P_{h}=0.46$ ). The recomputed combined estimates also remained stable which meant the results were unchanged (allele model: OR=1.01, 95\% Cl: 0.95 - 1.07; homozygous model: OR = 1.09, 95\% Cl: 0.97-1.22; heterozygous model: OR = 1.03, $95 \% \mathrm{Cl}$ : 0.96 1.11; dominant model: $\mathrm{OR}=0.99,95 \% \mathrm{Cl}$ : 0.92 - 1.08; recessive model: $\mathrm{OR}=1.07 \otimes 95 \varangle \mathrm{Cl} \otimes 0.97-1.17)$.

\section{Discussion}

Based on the key role of MMP-13 gene and the inconsistency of existing evidence, the current meta-analysis was conducted to systematically assess the relationship between rs 2252070 gene polymorphism of MMP-13 and cancer susceptibility. 16695 samples (including 8215 cases and 8480 controls) from 20 related datasets were analyzed. The results suggested that the association between rs2252070 polymorphism and the risk of cancer is insignificant.

Heterogeneity plays an important role in evaluating the strength of a meta-analysis and it should be eliminated as much as possible to avoid erroneous interpretation of analysis results. For our study, significant between-study heterogeneity had been detected in all five genetic models. Therefore, we performed subgroup analyses by cancer type, region, sample size and genotyping method. In subgroup analyses of cancer type, because of the diversity of included cancer types, we combined colorectal, esophageal, gastric cardia and oral cancer studies as digestive cancer subgroup. And except for lung cancer researches, the remaining ones were converged as another group. While there was still no significant differential cancer susceptibility between wild type and mutant type in none of the subgroups. In addition, considering that most of the included samples were from Asian area and even the same SNP can have a totally different effect among different races, we stratified the overall population according to geological source area and the results suggested no statistical difference had been found. As for stratified analyses based on genotyping method, no statistical significance in association between rs 2252070 and cancer risk had been detected. Similarly, no significant associations were found in neither subgroup when stratified according to sample size.

It should be noted that there were several limitations in our analysis. Firstly, only Chinese and English databases had been involved in the literature searching and screening process and this may lead the exclusion of other pertinent studies. On the other hand, most of the available studies we found were about Chinese populations, which restricted us to investigate potential biases caused by racial genetic differences. Secondly, another major limitation of the systematic review was the statistical heterogeneity between involved studies, which limited the ability to evaluate the size of the effects in a more precise way. Finally, due to data limitations, this study did not take the possible SNP-SNP and gene-gene interactions into consideration. Also, we didn't evaluate the impact of other confounding factors like alcohol or cigarette using.

In spite of the limitations mentioned above, the main superiority of high-quality meta-analysis was the methodology. No matter in the process of literature search, study screening, data extraction or result interpretation, we all adhered to the system evaluation and Meta-Analysis Guide (PRISMA) strictly[40]. Moreover, by integrating the data sets of previously published studies, the sample size of the study was expanded and possible small-sample-effect had been eliminated, which improved the statistical power greatly. Last but not least, by performing sensitivity analyses and publication bias analyses, the results of this meta-analysis were proved to be stable and reliable.

\section{Conclusion}

The results of this meta-analysis showed that there was no statistically significant association between MMP-13 rs2252070 and cancer susceptibility, suggesting the inappropriateness of listing this polymorphism as a biomarker for cancer risk. However, this is only a preliminary conclusion. Further designed studies with larger sample size are needed to clarify the relationship between rs2252070 polymorphism and cancer risk.

\section{Abbreviations}

SNP: single nucleotide polymorphism; OR: odds ratio; Cl: confidence interval; HWE: Hardy Weinberg equilibrium ; ECM: extracellular matrix.

\section{Declarations}

\section{Ethics approval and consent to participate}

This study was approved by the Institute Ethical Committee of the Affiliated Cancer Hospital of Zhengzhou University, China. Written informed consents were obtained from all patients.

\section{Consent for publication}

Not applicable.

\section{Avaliability of data and materials}

Not applicable.

\section{Competing interests}

The authors declare that they have no competing interests.

\section{Funding}


This project was supported by Henan Provincial Scientific and Technological Project (132300410041)

\section{Author's contributions}

PY and BX have designed the research and wrote the paper; YC, YM, CZ and PR searched and analyzed the data. All authors read and gave final approval of this version for publishing.

\section{Acknowledgements}

The authors thank all of the patients and families that enrolled in this study. The authors are grateful to all staffs who contributed to this study.

\section{References}

1. Sela-Passwell, N.; Rosenblum, G.; Shoham, T.; Sagi, I. Structural and functional bases for allosteric control of MMP activities: can it pave the path for selective inhibition? Biochim Biophys Acta 2010, 1803, 29-38, doi:10.1016/j.bbamcr.2009.04.010.

2. Ra, H.J.; Parks, W.C. Control of matrix metalloproteinase catalytic activity. Matrix Bio/ 2007, 26, 587-596, doi:10.1016/j.matbio.2007.07.001.

3. Thomas, G.T.; Lewis, M.P.; Speight, P.M. Matrix metalloproteinases and oral cancer. Oral Onco/ 1999, 35, 227-233, doi:10.1016/s1368-8375(99)00004-4.

4. Amălinei, C.; Căruntu, I.D.; Giuşcă, S.E.; Bălan, R.A. Matrix metalloproteinases involvement in pathologic conditions. Rom J Morphol Embryol 2010, 51, 215-228.

5. Nelson, A.R.; Fingleton, B.; Rothenberg, M.L.; Matrisian, L.M. Matrix metalloproteinases: biologic activity and clinical implications. J Clin Onco/ 2000, 18, 1135-1149, doi:10.1200/jco.2000.18.5.1135.

6. Johansson, N.; Ahonen, M.; Kähäri, V.M. Matrix metalloproteinases in tumor invasion. Cell Mol Life Sci 2000, 57, 5-15, doi:10.1007/s000180050495.

7. Freije, J.M.; Díez-Itza, I.; Balbín, M.; Sánchez, L.M.; Blasco, R.; Tolivia, J.; López-Otín, C. Molecular cloning and expression of collagenase-3, a novel human matrix metalloproteinase produced by breast carcinomas. J Biol Chem 1994, 269, 16766-16773.

8. Mitchell, P.G.; Magna, H.A.; Reeves, L.M.; Lopresti-Morrow, L.L.; Yocum, S.A.; Rosner, P.J.; Geoghegan, K.F.; Hambor, J.E. Cloning, expression, and type II collagenolytic activity of matrix metalloproteinase-13 from human osteoarthritic cartilage. J Clin Invest 1996, 97, 761-768, doi:10.1172/jci118475.

9. Leeman, M.F.; McKay, J.A.; Murray, G.I. Matrix metalloproteinase 13 activity is associated with poor prognosis in colorectal cancer. $J$ Clin Pathol 2002 , 55, 758-762, doi:10.1136/jcp.55.10.758.

10. Witty, J.P.; Foster, S.A.; Stricklin, G.P.; Matrisian, L.M.; Stern, P.H. Parathyroid hormone-induced resorption in fetal rat limb bones is associated with production of the metalloproteinases collagenase and gelatinase B. J Bone Miner Res 1996, 11, 72-78, doi:10.1002/jbmr.5650110111.

11. Yoon, S.; Kuivaniemi, H.; Gatalica, Z.; Olson, J.M.; Buttice, G.; Ye, S.; Norris, B.A.; Malcom, G.T.; Strong, J.P.; Tromp, G. MMP13 promoter polymorphism is associated with atherosclerosis in the abdominal aorta of young black males. Matrix Biol 2002, 21, 487-498, doi:10.1016/s0945-053x(02)00053-7.

12. Wang, R.C.L., X.Z.; Zhang, Y.X.; Zhang, J.M. . Expression and Clinical Singificance of MMP-13 in Breast Cancers by Tissue Microarray. International Journal of Pathology and Clinical Medicine 2009, 29, 469-472.

13. Leeman, M.F.; Curran, S.; Murray, G.I. The structure, regulation, and function of human matrix metalloproteinase-13. Crit Rev Biochem Mol Bio/ 2002, 37, 149-166, doi:10.1080/10409230290771483.

14. Mantel, N.; Haenszel, W. Statistical aspects of the analysis of data from retrospective studies of disease. J Natl Cancer Inst 1959, 22, 719-748.

15. DerSimonian, R.; Laird, N. Meta-analysis in clinical trials. Control Clin Trials 1986, 7, 177-188, doi:10.1016/0197-2456(86)90046-2.

16. Galbraith, R.F. A note on graphical presentation of estimated odds ratios from several clinical trials. Stat Med 1988, 7, 889-894, doi:10.1002/sim.4780070807.

17. Begg, C.B.; Mazumdar, M. Operating characteristics of a rank correlation test for publication bias. Biometrics 1994, 50, $1088-1101$.

18. Egger, M.; Davey Smith, G.; Schneider, M.; Minder, C. Bias in meta-analysis detected by a simple, graphical test. Bmj 1997, 315, 629-634, doi:10.1136/bmj.315.7109.629.

19. Li, Y.; Sun, D.L.; Duan, Y.N.; Zhang, X.J.; Wang, N.; Zhou, R.M.; Chen, Z.F.; Wang, S.J. Association of functional polymorphisms in MMPs genes with gastric cardia adenocarcinoma and esophageal squamous cell carcinoma in high incidence region of North China. Mol Biol Rep 2010, 37, 197-205, doi:10.1007/s11033-009-9593-4.

20. Zhou, G.; Zhai, Y.; Cui, Y.; Qiu, W.; Yang, H.; Zhang, X.; Dong, X.; He, Y.; Yao, K.; Zhang, H., et al. Functional polymorphisms and haplotypes in the promoter of the MMP2 gene are associated with risk of nasopharyngeal carcinoma. Hum Mutat 2007, 28, 1091-1097, doi:10.1002/humu.20570.

21. Zhang, X.-J.; Guo, W.; Wang, N.; Zhou, R.-M.; Dong, X.-J.; Li, Y. The association of MMP-13 polymorphism with susceptibility to esophageal squamous cell carcinoma and gastric cardiac adenocarcinoma. Yi chuan = Hereditas 2006, 28, 1500-1504, doi:10.1360/yc-006-1500.

22. Zhai, Y.; Qiu, W.; Dong, X.J.; Zhang, X.M.; Xie, W.M.; Zhang, H.X.; Yuan, X.Y.; Zhou, G.Q.; He, F.C. Functional polymorphisms in the promoters of MMP-1, MMP-2, MMP-3, MMP-9, MMP-12 and MMP-13 are not associated with hepatocellular carcinoma risk. Gut 2007, 56, 445-447, doi:10.1136/gut.2006.112706.

23. Yao, K. The Association of MMP-12 MMP-13Polymorphism with the Risk of Colorectal Cancer. Hebei Medical Uinversity, 2013.

24. Yang, F.Z., Z.J.; Zhao, Z.; Zhang, J.; Fu, K.; He, Y.T.; Jing, S.H. Association betwen polymorphisms on MMP-12and MMP-13 genes promoter region and genetic susceptibility to laryngeal squamous cell carcinoma CHIN J CANCER PREV TREAT 2014, 21, 1219-1222.

25. Wang, W.W., Z.C.; Liu, X.Y.; Wang, B.; Zeng, H.; Mi, L.L; Wang, R. Assosiation between matrix metalloproteinase 13 gene polymorphism and susceptibility to non-samall cell lung cancer China Journal of Modern Medicine 2013, 23, 35-39.

Page 5/14 
26. Vairaktaris, E.; Yapijakis, C.; Nkenke, E.; Serefoglou, Z.C.; Chatzitheofylaktou, A.; Vassiliou, S.; Derka, S.; Vylliotis, A.; Perrea, D.; Neukam, F.W., et al. A metalloproteinase-13 polymorphism affecting its gene expression is associated with advanced stages of oral cancer. Anticancer Res 2007, 27, 40274030.

27. Song Van, N.; Skarstedt, M.; Lofgren, S.; Zar, N.; Andersson, R.E.; Lindh, M.; Matussek, A.; Dimberg, J. Gene Polymorphism of Matrix Metalloproteinase-12 and-13 and Association with Colorectal Cancer in Swedish Patients. Anticancer Research 2013, 33, 3247-3250.

28. Shi, M.; Xia, J.; Xing, H.; Yang, W.; Xiong, X.; Pan, W.; Han, S.; Shang, J.; Zhou, C.; Zhou, L., et al. The Sp1-mediaded allelic regulation of MMP13 expression by an ESCC susceptibility SNP rs2252070. Sci Rep 2016, 6, 27013, doi:10.1038/srep27013.

29. Sanli, M.; Akar, E.; Pehlivan, S.; Bakir, K.; Tuncozgur, B.; Isik, A.F.; Pehlivan, M.; Elbeyli, L. The relationship of metalloproteinase gene polymorphisms and lung cancer. J Surg Res 2013, 183, 517-523, doi:10.1016/j.jss.2013.01.045.

30. Peng, J.C. Association of single nucleotide polymorphisms in the MMP-12 and MMP-13 genes with lung cancer. Hebei Medical Uinversity, 2010.

31. Moreno-Ortiz, J.M.; Gutierrez-Angulo, M.; Partida-Perez, M.; Peregrina-Sandoval, J.; Ramirez-Ramirez, R.; Muniz-Mendoza, R.; Suarez-Villanueva, S.; Centeno-Flores, M.; Maciel-Gutierrez, V.; Cabrales-Vazquez, J.E., et al. Association of MMP7-181A/G and MMP13-77A/G polymorphisms with colorectal cancer in a Mexican population. Genet Mol Res 2014, 13, 3537-3544, doi:10.4238/2014.February.14.1.

32. Lu, L.J. Studies on Correlation between Genetic Polymorphisms in Matrix Metalloproteinsase Genes and the Risk of Lung Cancer. Hunan University of Technology, 2017.

33. Li, W.; Jia, M.X.; Wang, J.H.; Lu, J.L.; Deng, J.; Tang, J.X.; Liu, C. Association of MMP9-1562C/T and MMP13-77A/G Polymorphisms with Non-Small Cell Lung Cancer in Southern Chinese Population. Biomolecules 2019, 9, doi:10.3390/biom9030107.

34. Lei, H.; Hemminki, K.; Altieri, A.; Johansson, R.; Enquist, K.; Hallmans, G.; Lenner, P.; Forsti, A. Promoter polymorphisms in matrix metalloproteinases and their inhibitors: few associations with breast cancer susceptibility and progression. Breast Cancer Res Treat 2007, 103, 61-69, doi:10.1007/s10549-0069345-2.

35. Jia, J.; Kang, S.; Zhao, J.; Zhang, X.; Wang, N.; Zhou, R.; Li, Y. Association of functional polymorphisms on MMP-12 and MMP-13 gene promoter region with epithelial ovarian carcinoma. Chin J Med Genet 2010, 27, 209-213, doi:10.3760/cma.j.issn.1003-9406.2010.02.020.

36. Gonzalez-Arriaga, P.; Lopez-Cima, M.F.; Fernandez-Somoano, A.; Pascual, T.; Marron, M.G.; Puente, X.S.; Tardon, A. Polymorphism +17 C/G in matrix metalloprotease MMP8 decreases lung cancer risk. BMC Cancer 2008, 8, 378, doi:10.1186/1471-2407-8-378.

37. Bialkowska, K.; Marciniak, W.; Muszynska, M.; Baszuk, P.; Gupta, S.; Jaworska-Bieniek, K.; Sukiennicki, G.; Durda, K.; Gromowski, T.; Prajzendanc, K., et al. Association of zinc level and polymorphism in MMP-7 gene with prostate cancer in Polish population. PLoS One 2018, 13, e0201065, doi:10.1371/journal.pone.0201065.

38. de Matos, F.R.; Santos, E.M.; Santos, H.B.P.; Machado, R.A.; Lemos, T.; Coletta, R.D.; Freitas, R.A. Association of polymorphisms in IL-8, MMP-1 and MMP13 with the risk and prognosis of oral and oropharyngeal squamous cell carcinoma. Arch Oral Biol 2019, 108, 104547, doi:10.1016/j.archoralbio.2019.104547.

39. Gao, X.; Huang, M.; Liu, L.; He, Y.; Yu, Q.; Zhao, H.; Zhou, C.; Zhang, J.; Zhu, Z.; Wan, J., et al. Insertion/deletion polymorphisms in the promoter region of BRM contribute to risk of hepatocellular carcinoma in Chinese populations. PLoS One 2013, 8, e55169, doi:10.1371/journal.pone.0055169.

40. Moher, D.; Shamseer, L.; Clarke, M.; Ghersi, D.; Liberati, A.; Petticrew, M.; Shekelle, P.; Stewart, L.A. Preferred reporting items for systematic review and metaanalysis protocols (PRISMA-P) 2015 statement. Syst Rev 2015, 4, 1, doi:10.1186/2046-4053-4-1.

\section{Tables}

Table 1: Principal characteristics of studies included in this meta-analysis. 


\begin{tabular}{|c|c|c|c|c|c|c|c|c|c|c|c|c|c|}
\hline \multirow[t]{2}{*}{ Author } & \multirow[t]{2}{*}{ Year } & \multirow{2}{*}{$\begin{array}{l}\text { Reference } \\
\text { ID }\end{array}$} & \multirow[t]{2}{*}{ Country } & \multirow[t]{2}{*}{ Region } & \multirow[t]{2}{*}{ Cancer Type } & \multirow{2}{*}{$\begin{array}{l}\text { Genotyping } \\
\text { Method }\end{array}$} & \multicolumn{3}{|c|}{ Cancer } & \multicolumn{3}{|c|}{ Control } & \multirow[t]{2}{*}{ HWE } \\
\hline & & & & & & & AA & $A G$ & GG & $\mathrm{AA}$ & AG & GG & \\
\hline Zhang & 2006 & [17] & China & China & Mixed & PCR-RFLP & 125 & 281 & 153 & 133 & 316 & 160 & 0.33 \\
\hline Lei & 2006 & [27] & Sweden & other & breast cancer & TaqMan & 443 & 408 & 103 & 449 & 417 & 84 & 0.36 \\
\hline Zhai & 2007 & [28] & China & China & $\begin{array}{l}\text { hepatocellular } \\
\text { cancer }\end{array}$ & DNA Sequencing & 99 & 212 & 116 & 123 & 225 & 129 & 0.22 \\
\hline Vairakataris & 2007 & [29] & $\begin{array}{l}\text { Greek } \\
\text { and } \\
\text { German }\end{array}$ & other & oral cancer & PCR-RFLP & 75 & 78 & 8 & 40 & 47 & 10 & 0.48 \\
\hline Zhou & 2007 & [30] & China & China & $\begin{array}{l}\text { nasopharyngeal } \\
\text { cancer }\end{array}$ & $\begin{array}{l}\text { polymerase chain } \\
\text { reaction (PCR) } \\
\text { direct sequencing }\end{array}$ & 201 & 367 & 200 & 195 & 353 & 204 & 0.09 \\
\hline \multirow[t]{2}{*}{$\begin{array}{l}\text { Gonzalez- } \\
\text { Arriaga }\end{array}$} & 2008 & [26] & Spain & Other & lung cancer & PCR-RFLP & 248 & 208 & 45 & 267 & 197 & 42 & \\
\hline & & & & & & & & & & & & & 0.51 \\
\hline Jia & 2010 & [31] & China & China & $\begin{array}{l}\text { epithelial ovarian } \\
\text { cancer }\end{array}$ & PCR-RFLP & 75 & 154 & 71 & 61 & 149 & 90 & 0.96 \\
\hline Li & 2010 & [24] & China & China & Mixed & PCR-RFLP & 136 & 293 & 163 & 137 & 324 & 163 & 0.31 \\
\hline \multirow[t]{2}{*}{ Peng } & 2010 & [32] & China & China & lung cancer & PCR-RFLP & 105 & 207 & 108 & 91 & 227 & 101 & \\
\hline & & & & & & & & & & & & & 0.08 \\
\hline Wang & 2013 & [16] & China & China & lung cancer & PCR-RFLP & 85 & 132 & 83 & 55 & 156 & 89 & 0.35 \\
\hline Sanli & 2013 & [33] & Turkey & other & lung cancer & $\begin{array}{l}\text { PCR-RFLP and } \\
\text { DNA sequencing }\end{array}$ & 118 & 7 & 7 & 80 & 0 & 0 & NA \\
\hline Yao & 2013 & [34] & China & China & colorectal cancer & PCR-LDR & 25 & 64 & 40 & 10 & 28 & 36 & 0.24 \\
\hline Nguyen & 2013 & [35] & Sweden & other & colorectal cancer & TaqMan & 185 & 158 & 42 & 276 & 276 & 67 & 0.87 \\
\hline $\begin{array}{l}\text { Moreno- } \\
\text { Ortiz }\end{array}$ & 2014 & [15] & Mexico & other & colorectal cancer & PCR-RFLP & 48 & 50 & 4 & 60 & 49 & 16 & 0.24 \\
\hline Yang & 2014 & [36] & China & China & $\begin{array}{l}\text { laryngeal } \\
\text { squamous cell } \\
\text { cancer }\end{array}$ & PCR-LDR & 32 & 61 & 55 & 20 & 56 & 72 & 0.1 \\
\hline Shi & 2016 & [37] & China & China & $\begin{array}{l}\text { esophageal } \\
\text { squamous cancer }\end{array}$ & MassArray & 259 & 730 & 599 & 348 & 821 & 431 & 0.25 \\
\hline Lu & 2017 & [38] & China & China & lung cancer & PCR-RFLP & 82 & 69 & 31 & 119 & 72 & 24 & 0.01 \\
\hline Bialkowska & 2018 & [39] & Polish & other & prostate cancer & TaqMan & 92 & 87 & 18 & 104 & 78 & 15 & 0.94 \\
\hline Li & 2019 & [25] & China & China & lung cancer & PCR-RFLP & 108 & 94 & 43 & 140 & 87 & 31 & $<0.01$ \\
\hline de-Matos & 2019 & [40] & Brazil & other & $\begin{array}{l}\text { oropharyngeal } \\
\text { squamous cell } \\
\text { cancer }\end{array}$ & TaqMan & 53 & 64 & 8 & 46 & 65 & 19 & 0.61 \\
\hline
\end{tabular}

Table 2: Association between the MMP-13 polymorphism and cancer risk 


\begin{tabular}{|c|c|c|c|c|c|c|c|c|c|c|c|c|c|c|}
\hline \multirow[t]{2}{*}{ Comparison } & \multicolumn{3}{|c|}{ Allele model (G vs. A) } & \multicolumn{3}{|c|}{$\begin{array}{l}\text { Homozygote model ( } \\
\text { GG vs. AA) }\end{array}$} & \multicolumn{3}{|c|}{$\begin{array}{l}\text { Heterozygote model } \\
\text { (AG vs. AA) }\end{array}$} & \multicolumn{3}{|c|}{$\begin{array}{l}\text { Dominant model (GG+AG vs. } \\
\text { AA) }\end{array}$} & \multicolumn{2}{|c|}{$\begin{array}{l}\text { Recessive model (GG vs } \\
\text { AA+AG) }\end{array}$} \\
\hline & $\begin{array}{l}\mathrm{OR}(95 \% \\
\mathrm{Cl})\end{array}$ & $P$ & $P_{h}$ & $\begin{array}{l}\text { OR } \\
(95 \% \\
\mathrm{Cl})\end{array}$ & $P$ & $P_{h}$ & $\begin{array}{l}\text { OR } \\
(95 \% \\
\text { Cl) }\end{array}$ & $P$ & $P_{h}$ & OR $(95 \% \mathrm{Cl})$ & $P$ & $P_{h}$ & OR $(95 \% \mathrm{Cl})$ & $P$ \\
\hline Overall & $\begin{array}{l}0.99 \\
(0.89 \\
1.10)\end{array}$ & 0.83 & $<0.01$ & $\begin{array}{l}0.96 \\
(0.78 \\
1.17)\end{array}$ & 0.67 & $<0.01$ & $\begin{array}{l}1.00 \\
(0.91 \\
1.10)^{\prime}\end{array}$ & 1.00 & 0.06 & $1.00(0.88,1.13)$ & 0.97 & $<0.01$ & $0.98(0.83,1.16)$ & 0.83 \\
\hline \multicolumn{15}{|l|}{ Region } \\
\hline China & $\begin{array}{l}1.00 \\
(0.87 \\
1.14)^{\prime}\end{array}$ & 0.95 & $<0.01$ & $\begin{array}{l}0.99 \\
(0.76 \\
1.28)\end{array}$ & 0.93 & $<0.01$ & $\begin{array}{l}0.98 \\
(0.85 \\
1.13)\end{array}$ & 0.78 & 0.02 & $\begin{array}{l}0.98(0.82 \\
1.17)\end{array}$ & 0.85 & $<0.01$ & $\begin{array}{l}1.02(0.84 \\
1.24)\end{array}$ & 0.87 \\
\hline Other & $\begin{array}{l}0.98 \\
(0.85 \\
1.13)\end{array}$ & 0.75 & 0.04 & $\begin{array}{l}0.88 \\
(0.61 \\
1.27)\end{array}$ & 0.51 & 0.02 & $\begin{array}{l}1.02 \\
(0.91 \\
1.14)^{\prime}\end{array}$ & 0.76 & 0.41 & $\begin{array}{l}1.03(0.92 \\
1.15)\end{array}$ & 0.65 & 0.18 & $\begin{array}{l}0.88(0.62 \\
1.25)\end{array}$ & 0.47 \\
\hline \multicolumn{15}{|l|}{$\begin{array}{l}\text { Cancer } \\
\text { Type }\end{array}$} \\
\hline lung & $\begin{array}{l}1.13 \\
(0.89 \\
1.43)\end{array}$ & 0.31 & $<0.01$ & $\begin{array}{l}1.19 \\
(0.79 \\
1.79)\end{array}$ & 0.42 & $<0.01$ & $\begin{array}{l}1.02 \\
(0.73 \\
1.43)\end{array}$ & 0.89 & $<0.01$ & $\begin{array}{l}1.09(0.77 \\
1.55)\end{array}$ & 0.64 & $<0.01$ & $\begin{array}{l}1.16(0.97 \\
1.38)\end{array}$ & 0.11 \\
\hline digestive & $\begin{array}{l}0.95 \\
(0.80 \\
1.12)\end{array}$ & 0.51 & $<0.01$ & $\begin{array}{l}0.85 \\
(0.60 \\
1.20)^{\prime}\end{array}$ & 0.36 & $<0.01$ & $\begin{array}{l}1.03 \\
(0.92 \\
1.14)\end{array}$ & 0.64 & 0.50 & $\begin{array}{l}1.00(0.84 \\
1.18)\end{array}$ & 0.96 & 0.02 & $\begin{array}{l}0.86(0.64 \\
1.16)\end{array}$ & 0.33 \\
\hline others & $\begin{array}{l}0.94 \\
(0.80 \\
1.10)\end{array}$ & 0.44 & 0.02 & $\begin{array}{l}0.89 \\
(0.65 \\
1.23)\end{array}$ & 0.49 & 0.03 & $\begin{array}{l}0.99 \\
(0.87 \\
1.13)^{\prime}\end{array}$ & 0.86 & 0.53 & $\begin{array}{l}0.98(0.87 \\
1.11)\end{array}$ & 0.80 & 0.15 & $\begin{array}{l}0.91(0.72 \\
1.17)\end{array}$ & 0.48 \\
\hline \multicolumn{15}{|l|}{ Method } \\
\hline PCR-PFLP & $\begin{array}{l}1.01(0.88 \\
1.15)\end{array}$ & 0.93 & $<0.01$ & $\begin{array}{l}0.95 \\
(0.73 \\
1.23)\end{array}$ & 0.71 & $<0.01$ & $\begin{array}{l}0.98 \\
(0.82 \\
1.16)\end{array}$ & 0.81 & 0.02 & $\begin{array}{l}0.99(0.82 \\
1.19)\end{array}$ & 0.88 & $<0.01$ & $\begin{array}{l}1.02(0.84 \\
1.23)\end{array}$ & 0.88 \\
\hline others & $\begin{array}{l}0.96(0.82 \\
1.13)\end{array}$ & 0.66 & $<0.01$ & $\begin{array}{l}0.95 \\
(0.69 \\
1.31)\end{array}$ & 0.76 & $<0.01$ & $\begin{array}{l}1.04 \\
(0.94 \\
1.14)\end{array}$ & 0.45 & 0.44 & $\begin{array}{l}1.02(0.86 \\
1.20)\end{array}$ & 0.85 & $<0.01$ & $\begin{array}{l}0.94(0.71 \\
1.24)\end{array}$ & 0.65 \\
\hline \multicolumn{15}{|l|}{$\begin{array}{l}\text { Sample } \\
\text { Size }\end{array}$} \\
\hline$>1000$ & $\begin{array}{l}1.07 \\
(0.94 \\
1.21)\end{array}$ & 0.31 & $<0.01$ & $\begin{array}{l}1.15 \\
(0.91 \\
1.47)\end{array}$ & 0.24 & $<0.01$ & $\begin{array}{l}1.02 \\
(0.94 \\
1.12)\end{array}$ & 0.62 & 0.43 & $\begin{array}{l}1.06(0.92 \\
1.21)\end{array}$ & 0.44 & 0.02 & $\begin{array}{l}1.15(0.95 \\
1.40)\end{array}$ & 0.16 \\
\hline$<=1000$ & $\begin{array}{l}0.93 \\
(0.79 \\
1.09)\end{array}$ & 0.37 & $<0.01$ & $\begin{array}{l}0.81 \\
(0.59 \\
1.11)\end{array}$ & 0.19 & $<0.01$ & $\begin{array}{l}0.99 \\
(0.82 \\
1.19)\end{array}$ & 0.88 & 0.03 & $\begin{array}{l}0.94(0.76 \\
1.17)\end{array}$ & 0.60 & $<0.01$ & $\begin{array}{l}0.85(0.67 \\
1.09)\end{array}$ & 0.20 \\
\hline
\end{tabular}

\section{Figures}




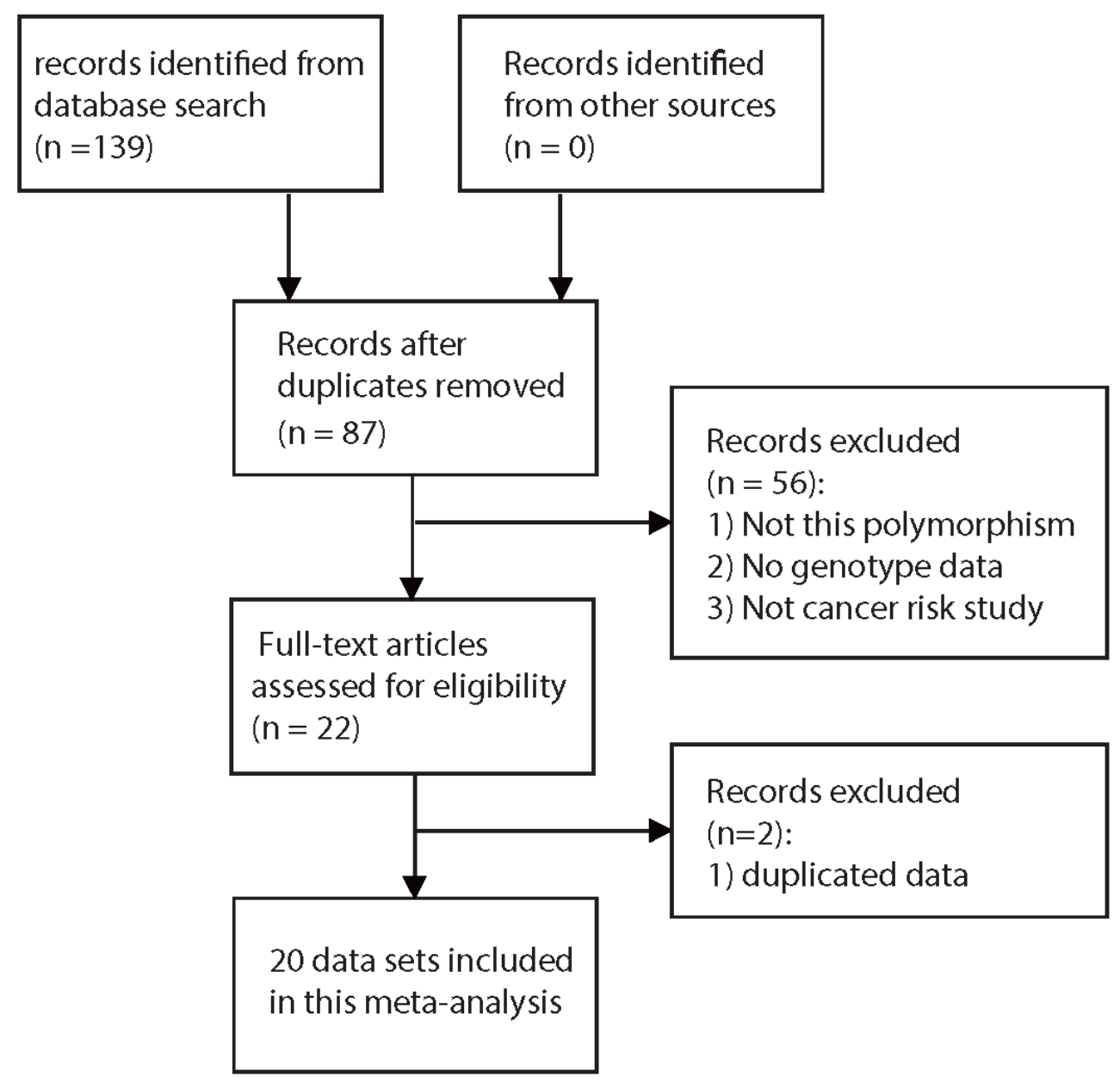

Figure 1

Flowchart shows detailed processes of literature screening. 


\begin{tabular}{|c|c|c|c|c|c|c|c|c|c|c|}
\hline Study & \multicolumn{2}{|c|}{$\begin{array}{l}\text { Experimental } \\
\text { Events Total }\end{array}$} & \multicolumn{2}{|c|}{$\begin{array}{r}\text { Control } \\
\text { ents Total }\end{array}$} & Odds Ratio & \multicolumn{3}{|c|}{$95 \%-\mathrm{Cl}$} & $\begin{array}{l}\text { Weight } \\
\text { (fixed) }\end{array}$ & $\begin{array}{r}\text { Weight } \\
\text { (random) }\end{array}$ \\
\hline \multicolumn{11}{|l|}{ digestive cancer } \\
\hline Zhang 2006 & 281 & 406 & 316 & 449 & T & 0.95 & {$[0.71$} & 1.27] & $6.4 \%$ & $6.6 \%$ \\
\hline Zhai 2007 & 212 & 311 & 225 & 348 & & 1.17 & {$[0.85$} & 1.62] & $4.7 \%$ & $5.8 \%$ \\
\hline Vairakataris 2007 & 78 & 153 & 47 & 87 & & 0.89 & {$[0.52$} & $1.50]$ & $2.0 \%$ & $2.8 \%$ \\
\hline Li 2010 & 293 & 429 & 324 & 461 & & 0.91 & {$[0.69$} & 1.21] & $6.9 \%$ & $6.8 \%$ \\
\hline Yao 2013 & 64 & 89 & 28 & 38 & & 0.91 & {$[0.39$} & $2.15]$ & $0.8 \%$ & $1.2 \%$ \\
\hline Nguyen 2013 & 158 & 343 & 276 & 552 & I & 0.85 & {$[0.65$} & 1.12] & $7.9 \%$ & $7.2 \%$ \\
\hline Moreno-Ortiz 2014 & 50 & 98 & 49 & 109 & & 1.28 & {$[0.74$} & $2.20]$ & $1.6 \%$ & $2.7 \%$ \\
\hline Shi 2016 & 730 & 989 & 821 & 1169 & & 1.19 & {$[0.99$} & $1.44]$ & $13.7 \%$ & $10.0 \%$ \\
\hline de-Matos 2019 & 64 & 117 & 65 & 111 & & 0.85 & {$[0.51$} & $1.44]$ & $2.1 \%$ & $2.9 \%$ \\
\hline Fixed effect model & & 2935 & & 3324 & & 1.03 & {$[0.92$} & 1.14] & $46.1 \%$ & - \\
\hline Random effects model & & & & & & 1.03 & {$[0.92$} & $1.14]$ & -- & $46.0 \%$ \\
\hline \multicolumn{11}{|c|}{ Heterogeneity: $I^{2}=0 \%, \tau^{2}=0, p=0.50$} \\
\hline \multicolumn{11}{|l|}{ lung cancer } \\
\hline Gonzalez-Arriaga 2008 & 208 & 456 & 197 & 464 & $\frac{1}{1}$ & 1.14 & {$[0.88$} & 1.47] & $7.4 \%$ & $7.5 \%$ \\
\hline Peng 2010 & 207 & 312 & 227 & 318 & $\frac{7}{4}$ & 0.79 & {$[0.56$} & 1.11] & $5.3 \%$ & $5.5 \%$ \\
\hline Wang 2013 & 132 & 217 & 156 & 211 & $\mp$ & 0.55 & {$[0.36$} & $0.83]$ & $4.3 \%$ & $4.2 \%$ \\
\hline Sanli 2013 & 7 & 125 & 0 & 80 & & 10.19 & {$[0.57 ; 18$} & 80.92] & $0.0 \%$ & $0.1 \%$ \\
\hline Lu 2017 & 69 & 151 & 72 & 191 & $\Psi$ & 1.39 & {$[0.90$} & $2.15]$ & $2.4 \%$ & $3.9 \%$ \\
\hline Li 2019 & 94 & 202 & 87 & 227 & + & 1.40 & {$[0.95$} & $2.06]$ & $3.0 \%$ & $4.6 \%$ \\
\hline Fixed effect model & & 1463 & & 1491 & & 1.02 & {$[0.88$} & 1.19] & $22.4 \%$ & - \\
\hline Random effects model & & & & & 8 & 1.02 & {$[0.73$} & $1.43]$ & - & $25.8 \%$ \\
\hline \multicolumn{11}{|c|}{ Heterogeneity: $I^{2}=73 \%, \tau^{2}=0.1117, p<0.01$} \\
\hline \multicolumn{11}{|l|}{ other } \\
\hline Lei 2006 & 408 & 851 & 417 & 866 & $1+$ & 0.99 & {$[0.82$} & 1.20] & $14.9 \%$ & $10.0 \%$ \\
\hline Zhou 2007 & 367 & 568 & 353 & 548 & +1 & 1.01 & {$[0.79$} & 1.29] & $8.8 \%$ & $8.0 \%$ \\
\hline Jia 2010 & 154 & 229 & 149 & 210 & $\frac{1}{4}$ & 0.84 & {$[0.56$} & $1.26]$ & $3.5 \%$ & $4.3 \%$ \\
\hline Yang 2014 & 61 & 93 & 56 & 76 & $\rightarrow$ & 0.68 & {$[0.35$} & 1.33] & $1.5 \%$ & $1.9 \%$ \\
\hline Bialkowska 2018 & 87 & 179 & 78 & 182 & 世 & 1.26 & {$[0.83$} & 1.91] & $2.8 \%$ & $4.1 \%$ \\
\hline Fixed effect model & & 1920 & & 1882 & $\gamma$ & 0.99 & {$[0.87$} & 1.13] & $31.5 \%$ & - \\
\hline Random effects model & & & & & 8 & 0.99 & {$[0.87$} & 1.13] & -- & $28.3 \%$ \\
\hline \multicolumn{11}{|c|}{ Heterogeneity: $I^{2}=0 \%, \tau^{2}=0, p=0.53$} \\
\hline Fixed effect model & & 6318 & & 6697 & $\oint$ & 1.01 & {$[0.94$} & $1.09]$ & $100.0 \%$ & - \\
\hline Random effects model & & & & & $\phi$ & 1.00 & {$[0.91$} & 1.10] & - & $100.0 \%$ \\
\hline Heterogeneity: $I^{2}=35 \%, \tau^{2}$ & ${ }^{2}=0.0157$ & $p=0$ & & $\Gamma$ & $T$ & 1 & & & & \\
\hline Residual heterogeneity: $I^{2}=$ & $=42 \%, p$ & $=0.03$ & & 0.01 & 0.1 & 100 & & & & \\
\hline
\end{tabular}

\section{Figure 2}

Forest plot shows the association between MMP-13 RS2252070 polymorphism and cancer risk under heterozygous model. The results were calculated using a random effects model. Each square represents an independent study, and the first author's last name and year of publication for each study were noted. The center of the square corresponds to its Odds ratio (OR), the range of horizontal lines corresponds to the $95 \%$ confidence interval ( $95 \% \mathrm{Cl}$ ). The area of the square is proportional to the combined weight (shown in the weight column). The bottom diamond represents the pooled result, the center of the diamond corresponds to the pooled Odds ratio (OR), and the left and right vertices of the diamond correspond to the $95 \%$ confidence interval (95\% $\mathrm{Cl}$ ). An invalid vertical line $(\mathrm{OR}=1)$ intersected by a diamond indicates that the result is not statistically significant. 


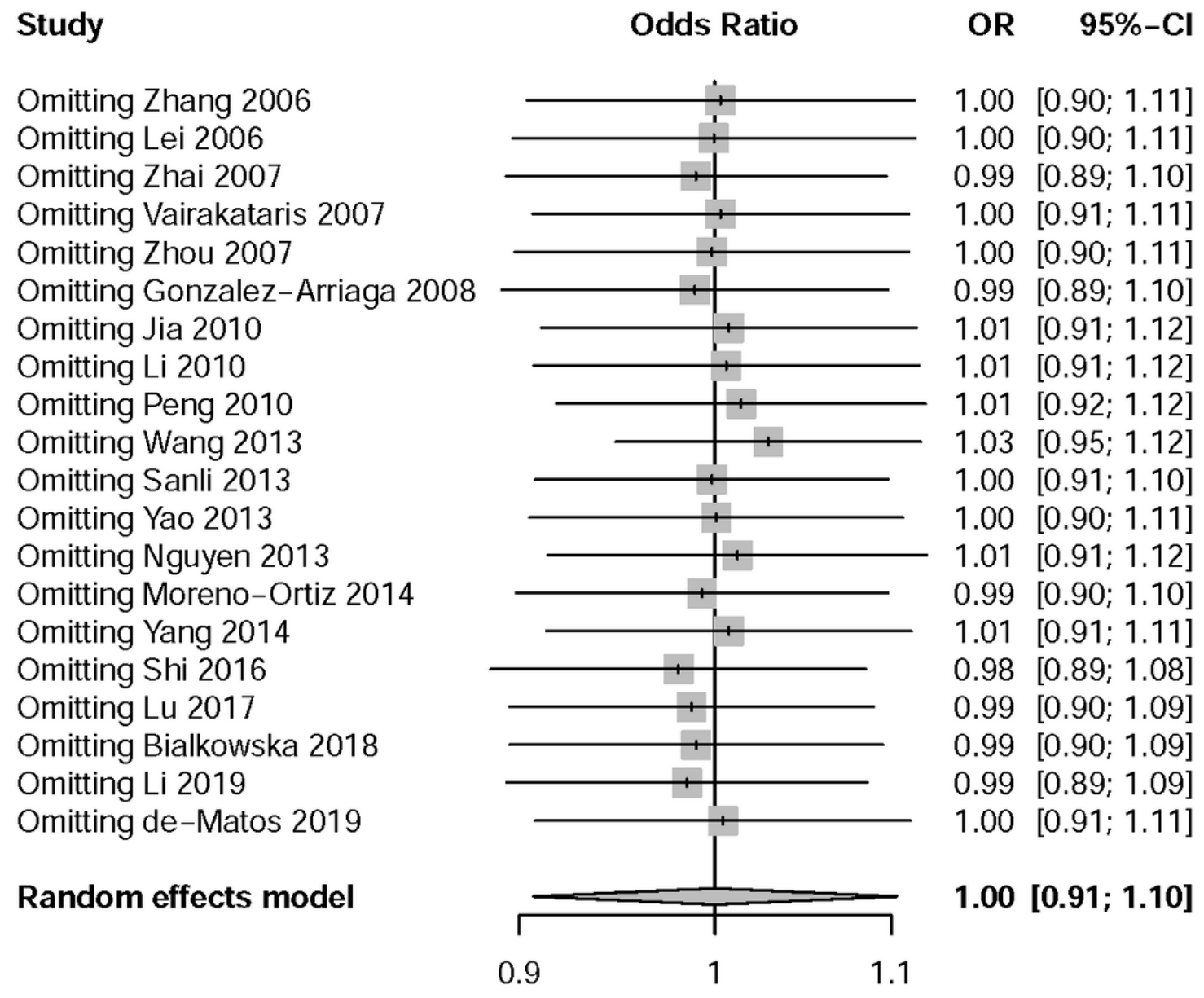

Figure 3

Forest plot of sensitivity analysis of MMP-13 RS2252070 polymorphism under heterozygote model with random effects. Row represents the pooled odds ratio $(\mathrm{OR})$ and corresponding $95 \%$ confidence interval $(95 \% \mathrm{Cl})$ of all studies after eliminating the corresponding study for each row. 
Begg's funnel plot with pseudo $95 \%$ confidence limits

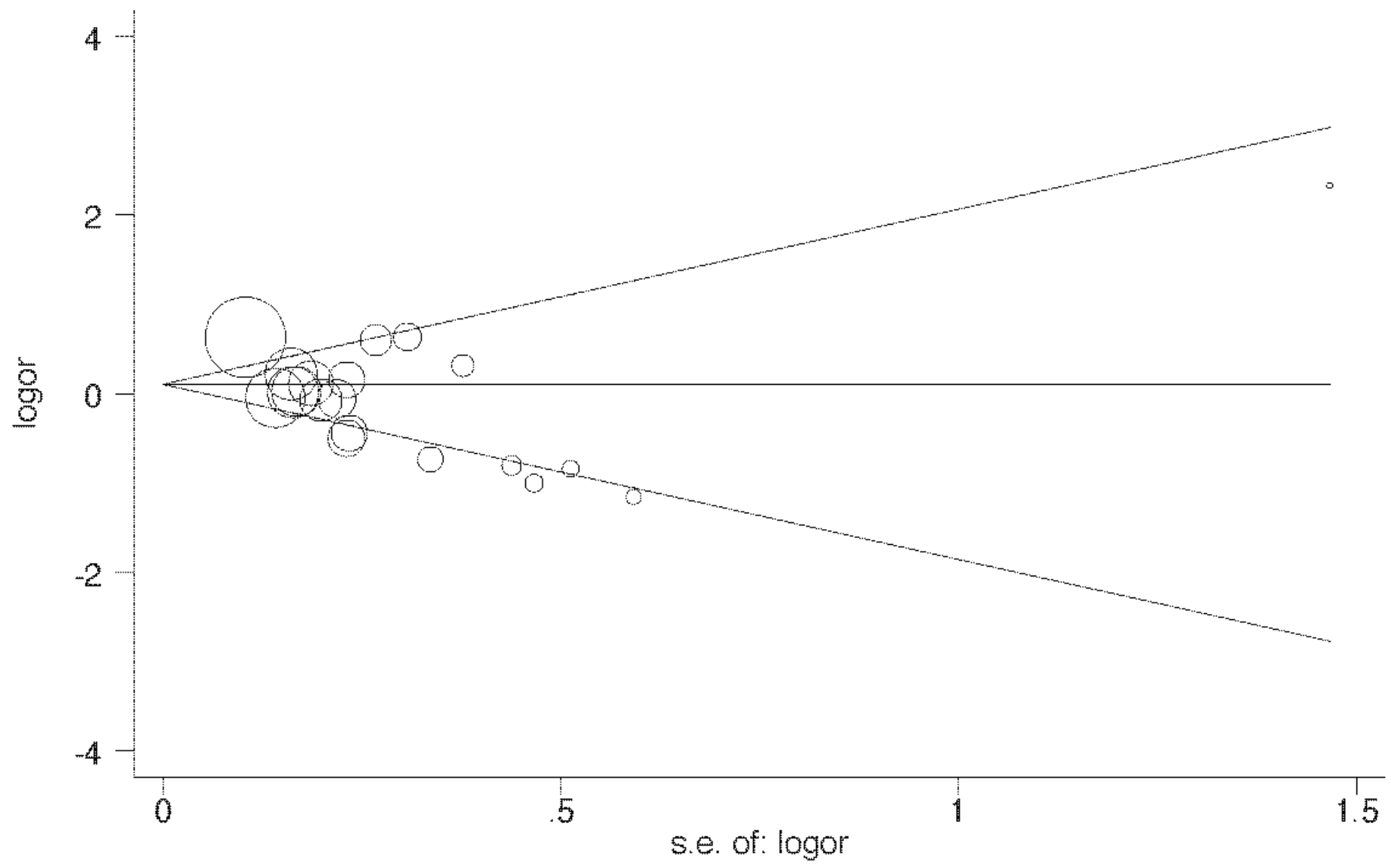

\section{Figure 4}

Funnel plot represents the results of the meta-analysis of MMP-13 rs2252070 polymorphism under heterozygous model using begg method. The X-axis represents the standard error of the log OR, and the Y-axis represents the log odds ratio (OR) stands. Each circle in the figure represents a study, and the size of the circle is proportional to the size of the sample. 
Begg's funnel plot with pseudo $95 \%$ confidence limits

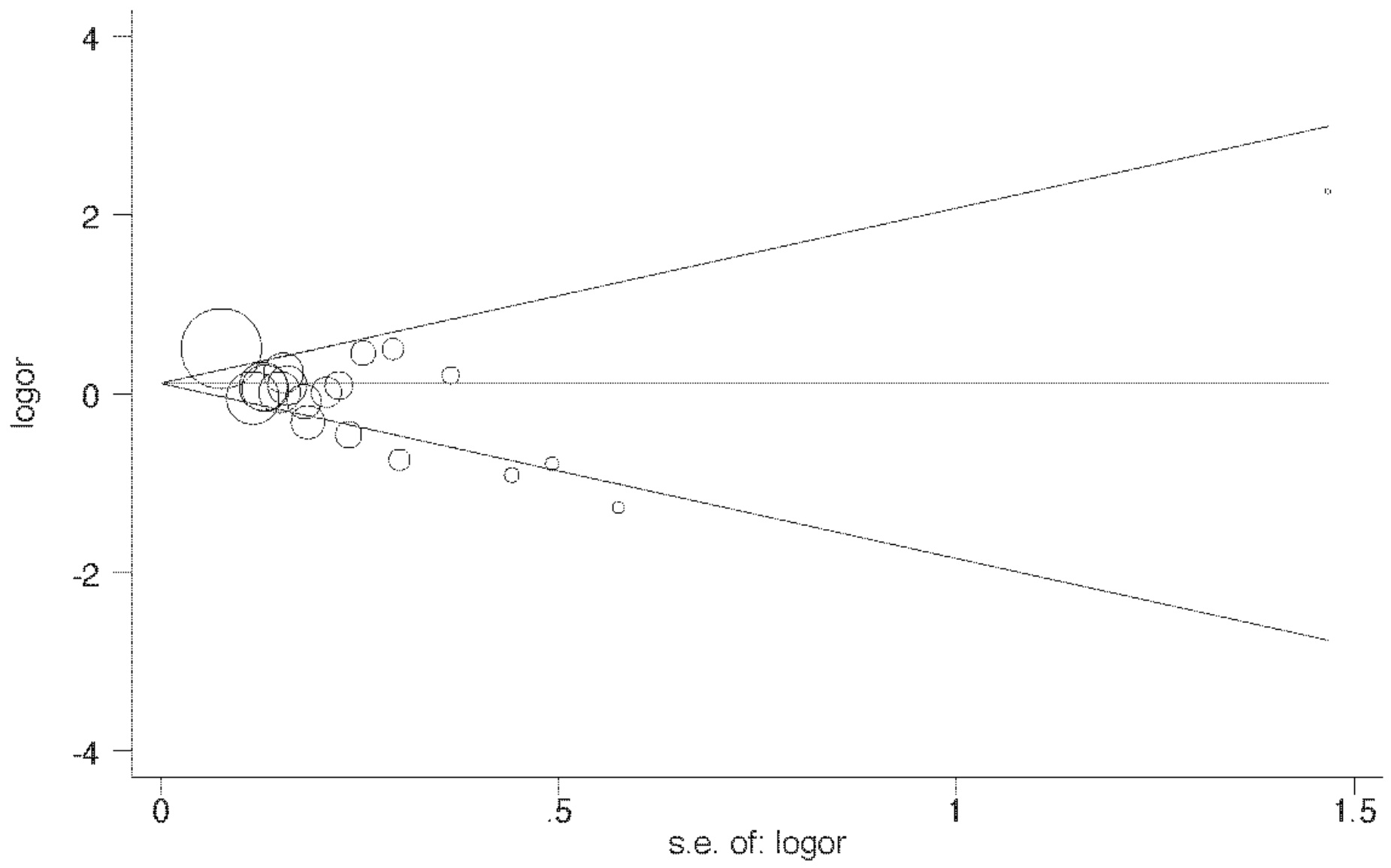

\section{Figure 5}

Funnel plot represents the results of the meta-analysis of MMP-13 rs2252070 polymorphism under recessive model using begg method. The X-axis represents the standard error of the log $\mathrm{OR}$, and the $\mathrm{Y}$-axis represents the log odds ratio (OR) stands. Each circle in the figure represents a study, and the size of the circle is proportional to the size of the sample. 


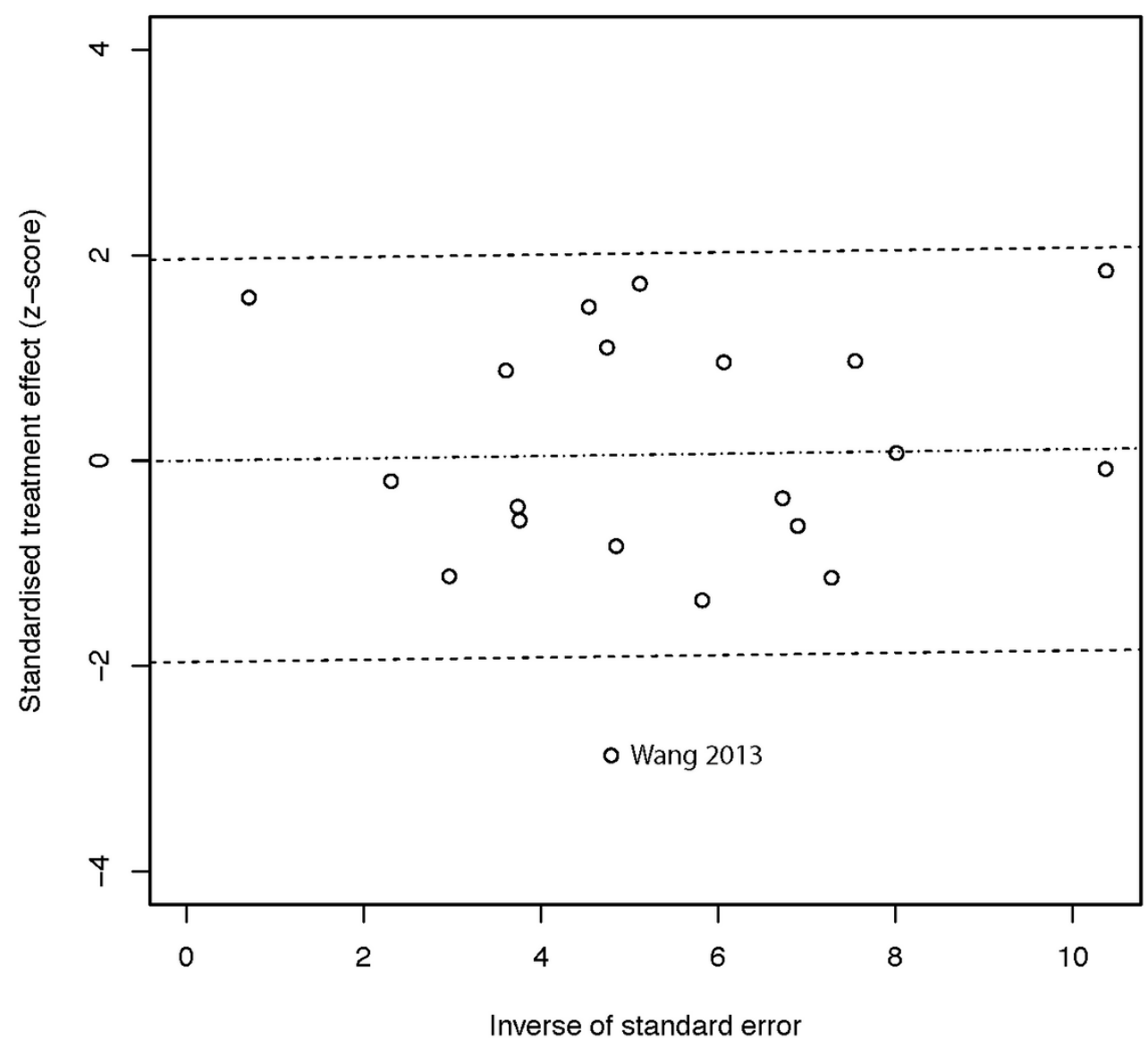

Figure 6

The Galbraith diagram shows the heterogeneity analysis results of MMP-13 rs2252070 under heterozygote model. The X-axis represents the inverse of the standard error of the effect value, and the $\mathrm{Y}$-axis is the standardized treatment effect (z-score). Each point represents a study. There are three oblique lines in the figure, the slope of the middle line represents the pooled value of the random effect, and the line on both sides represents the $95 \%$ confidence interval (95\% $\mathrm{Cl}$ ). Studies outside the bilateral line indicate the source of inter-study heterogeneity. They were tagged with the first author's last name and year of publication. 